of the salicylate it appears that the danger of acetonuria is obviated by giving at the same time bicarbonate of sodium in an equal or a larger amount. As it is necessary to test for the acetone, and such means are not always at hand to the busy country practitioner, it might be inquired whether the rough-and-ready test for alkalinity would not be to a certain extent a safeguard from acetone poisoning in cases where very large doses of the salicylate are deemed advisable.

Lymington, Hants.

\section{A CASE OF TABES DORSALIS IN WHICH WIDESPREAD CUTANEOUS SENSORY MANIFESTATIONS COMPLETELY DISAPPEARED.}

BY FREDERICK W. PRICE, M.B. EDIN., M.R.C.P. LOND., MEDICAL REGISTRAR TOO WESTMINSTER HOSPITAL.

THERE is a good deal of difference of opinion regarding the question whether the prognosis of the incoördination in tabes dorsalis is influenced by the presence or absence of optic atrophy. Thus, while many writers maintain that with the development of eye symptoms the ataxia often remains stationary, Dr. D. Ferrier in the recent Lumleian lectures expressed the opinion that all that could justifiably be said was that the ataxic and amaurotic forms of tabes are often more or less distinct though not exclusive of each other. Not so much attention has been given to the point as to whether the sensory disturbances are affected by the presence or absence of eye changes. In his lectures Dr. Ferrier pointed out that there is no constant relation between the degree of ataxia and the extent to which cutaneous sensibility is affected. The following case of tabes dorsalis is remarkable, inasmuch as marked sensory disturbances com pletely disappeared, apparently coincidently with the development of complete optic atrophy.

A man, 34 years of age, by occupation a warehouseman who had formerly been a soldier, was admitted to the Westminster Hospital under the care of Dr. R. G. Hebb on Angust 1st, 1905, complaining of weakness and numbness of the legs. There was nothing of note in the family history. The following personal history was obtained from the patient. At the age of 24 years, while in Burma, he had dysentery and malaria; during the same year he contracted syphilis, which was treated for a period of three weeks; there were very few, if any, secondary manifestations. Between two and three years before admission the patient noticed that his sight was failing and this failure of vision gradually increased. About a year ago he found that his gait was becoming unsteady and that be swayed on closing his eyes during the act of washing his face. Soon after this he began to feel numb in the feet, and later successively in the back of the legs, thighs, lower part of the scrotum and fingers. For some months there had been dribbling away of urine on laughing or coughing, and during the last month there had been an aching pain in the lower part of the cervical region after much movewent of the head. $\mathrm{He}$ had never suffered from lightning pains or from any crises.

On admission the patient was found to be a well-developed man, with a scar, the result of a bullet wound in 1900, in the lower part of the left calf. There was paræsthesia of the feet and tips of the fingers. There was almost complete loss of sensibility to touch, heat and cold, and pain in both legs up to the level of the knees; above that level there was partial aræsthesia up to, and including, the neck and posterior part of the head. Romberg's sign was very evident, the patient almost falling when the feet were put together, even with the eyes open; the gait was typical and very ataxic; there was slight inccördination of the upper extremities. The knee, triceps, and supinator jerks were all absent; the plantar reflex was abolished. There was some loss of control of the bladder sphincter but not of the rectal sphincter. There was slight diwinution of visual acuity ; the colour sense was normal; the external ocular movements were normal ; the pupils were equal, moderately dilated, and reacted both to light and to accommodation. Nothing abnormal was found on examination of the heart, the lungs, or the urine.

Iodide of potassium was ordered internally and a drachm of blue ointment was rubbed into the abdominal wall each

evening. Frenkel's exercises were regularly carried out. On August 21 st the anæsthesia was found to have somewhat altered, the patient could slightly feel pain over the inner aspects of the knees, and easily recognised touch and pain over both groins; apart from this there was almost complete loss of sensibility as high as the neck and the right half of the face was also less sencitive than normal.

The patient left the hospital on August 25th, his condition having moderately improved. He remained about the same until Christmas, when a steady loss of the power of vision commenced, so that by the middle of April he was totally unable to read, as he said the letters were obscured by lines which crossed one another "like the meshes of a net." He also said that the unsteadiness of gait had steadily increased; the difficulty in regard to his vesical sphincter had, on the other hand, continuously improved, so that there was no longer any trouble with his micturition.

The patient was readmitted on A pril 30th, 1906. The sensory functions were now found to be absolutely normal ; there were no paræsthesia and no impairment of sensibility to touch, heat and cold, or pain; the rate of conduction was normal and there were no pains in any part of the body. Romberg's sign was present; the ataxia of the lower limbs was so great that the patient could scarcely walk without support; he was able to perform fine movements with the upper limbs perfectly well. The plantar reflex and the knee and triceps jerks were all absent. The vesical and rectal sphincters acted normally. With both eyes open the patient was able to distinguish two fingers at a distance of four inches from the eyes; both pupils were of good size, the right being perhaps a little larger than the left; neither was absolutely circular ; both reacted to light and accommodation; complete optic atrophy was present. A lumbar puncture was performed and examination of the cerebrospinal fluid showed an extreme leucocytosis, most being small monomorphs (lymphocytes); of large monomorphs a considerable number also ; and the presence of a few polymorphs, no doubt due to admixture with blood. Osazon crystals of the thistle-down type were present; the fluid reduced Fehling's solution. The patient was put on the same treatment as before and was discharged on May 24th slightly improved.

It will be observed that the first symptom noticed by the patient was failure of sight. I regret that his discs were not examined when he came under observation on the first occasion, but it is probable that at that time his power of vision was not severely affected, so that optic atrophy, if present, was in all probability slight. Be that as it may, it is evident that in the space of eight months, coincidently with the development of practically complete optic atrophy, the sensory defects not only became arrested but actually disappeared, whilst along with the return of the sensory and bladder functions to the normal there was no improvement but rather a steady deterioration in the ccördinating functions. Although Argyll-Robertion phenomenon was not present during the times the patient was under observation, there can be no doubt regarding the diagnosis as the other symptoms were so characteristic.

I am indebted to Dr. Hebb for being allowed to publish this case.

Wimpole-street, W.

\section{A. âtirtor}

\section{HOSPITAL PRACTIOE BRITISH AND FOREIGN.}

Nuils autem est alia pro certo noscendi via, nisi quamplurimas et morborum et dissectionum historias, tum aliorum tum proprias collectas habere, et inter se comparare.-MoRG $1 \mathrm{GNI}$ De Sed. et Caus. Morb., lib. iv., Procmium.

\section{LEWISHAM INFIRMARY.}

\section{A CASE OF TETANUS WITH SUDDEN ONSET OF ACUTE} SYMPTOMS.

(Under the care of Dr. J. HobaRT NrXoN.)

A WELL-NounIsHed male child, aged four years, was taken to the infirmary at $8.10 \mathrm{~A} . \mathrm{M}$. on July 3rd last suffering from "convulsions." The child was in the position known 
as opisthotonos. He was bathed in profuse perspiration and the jaws were tightly clenched. His temperature was $99^{\circ} \mathrm{F}$. and the pulse at the radial artery could not be felt. Morphine was administered hypodermically and there were a few short intervals in the spasms and the child died at $9.35 \mathrm{~A} . \mathrm{M}$. the same day.

The history, obtained from the mother, was as follows. On the evening of June 27 th the child whilst playing ran a splinter of wood into his leg. The father withdrew the splinter and bathed the leg with a solution of boric acid. Three days later, as the wound did not heal, medical advice was obtained though the child did not complain of any pain but played about apparently in his usual health. Fomentations were applied and the wound healed. During the afternoon of July 2nd the child complained of "feeling funny in his stomach" but the uneasiness was not sufficient to interfere with his games. The discomfort was more marked in the evening but the child ate several biscuits and sweets before going to bed about 8 P.M. The mother visited the child about midnight when he complained of acute pain in the stomach and in the back of his neck. Soon afterwards convulsions set in and the medical attendant was sent for about 5 A.M. on July 3rd and ordered his removal to the infirmary.

Necropsy. - The post-mortem examination revealed the following conditions. On the outer side of the right leg, situated half-way between the ankle and the knee, was a dry, healed wound, roughly circular in shape and somewhat less than a quarter of an inch in diameter. The presence of any foreign body under the wound could not be felt. But on dissection a narrow track, one and a quarter inches in length, was revealed, at the bottom of which was found a splinter of rough, dirty wood three-quarters of an inch in length. Surrounding the splinter was a small cavity containing pus in which microscopic examination revealed the presence of typical bacilli tetani. Running through the wall of the cavity was a swollen nerve. The stomach was empty and showed no signs of irritztion. The meninges and lungs were congested. All other organs were normal.

Remarks by Dr. NIXON.-The points of particular interest about the case are: 1 . The superficial healing of the wound, rendering it impossible to tell by palpation that a foreign body was inclosed, though probing would have assisted the diagnosis had the child been taken to a medical man in the first instance. 2. The onset of symptoms was so sudden as to suggest poisoning; the child was playing as usual the previous evening, ate his supper, but died at $9.35 \mathrm{~A} . \mathrm{M}$. on the next morning. 3. The position of the nerve to the nidus of infection offered a ready means of transit of the toxin from the lesion of the splinter to the central nervous system.

\section{MELBOURNE HOSPITAL.}

A CASE OF A BULLET LODGED IN THE RIGHT HEART; LIFE CONTINUEJ FOR SIX MONTHS.

(Under the care of Dr. C. S. RYAN and Dr. H. C. MAUDSLEY.)

Fon the notes of the case we are indebted to Dr. Arthur Morris, late resident medical officer to the hospital.

A man, aged 70 years, and well preserved for his years' was admitted to a surgical ward of the Melbourne Hospital on Jan. 19th, 1904. He had been suffering from tabes dorsalis for the previous 16 years and had, apparently on account of the pains, attempted suicide on Jan. 18th by shooting himself in the lower part of the thorax with a revolver. Examination showed a bullet wound, with edges inverted and the skin blackened around it, situated at the level of the junction of the xiphisternum and the body of the sternum. There was very little hæmorrhage from the wound. The abdomen was lax, was not tender in any part, and there had been no vomiting. The patient complained of some pain between the shoulders posteriorly and also beneath the left nipple, while there was tenderness about the site of the wound. The direction taken by the bullet was apparently downwards, backwards, and to the left. On examination with the $x$ rays, using the screen, the bullet was seen to be situated about two inches to the left of the sternum and opposite the sixth left costal cartilage. The patient had no symptoms which called for operative inter. ference and was discharged on Feb. 2nd none the worse, apparently, for his experience.

Nothing further was seen of the patient until Sept. 17th,
1904, when he was admitted to a medical ward in the hospital in an unconscious condition. The history then obtainable was that he had suddenly become unconscious that morning and that the seizure had not been accompanied by any form of convulsion. On examination no reflexes, except the conjunctival, were obtainable. The heart's apex beat was in the sixth interspace, one inch outside the nipple line. The heart sounds were very weak but clear. No bruit could be detected. The second sound at the base was accentuated. The pulse was very small and rapid, with a tendency to be irregular. At this time the previous history was not known and the case was regarded as one of sudden senile heart failure. Appropriate treatment was adopted, but although the patient regained consciousness he died suddenly with marked dyspncea and cyanosis about four hours after his admission to the hospital.

Necropsy. - There was an old skin scar situated over the lower end of the sternum on a level with the fifth left costal cartilage and corresponding to this on the inner surface of the sternum was a patch of old organised hæmorrhage. The visceral and parietal layers of the pericardium were adherent to each other nearly all over. These adhesions were not very tough, one near the apex being firmer than the rest, while those over the right heart were dark and pigmented. A darkly pigmented cicatrix was present in the anterior wall of the right auricle close to the auriculo. ventricular groove and corresponding to this on the inner surface of the auricle was a small pigmented patch. The bullet must then have pierced the right anterior cusp of the tricuspid valve, leaving a small slit-like opening. On opening the right ventricle the bullet was found lodged and partly buried in the columnæ carneæ of the apex. Part of the buliet projected into the right ventricle and was covered by a thin filmy membrane. The whole of the heart muscle was flabby and the left ventricle was dilated and hypertrophied-a kidney heart in not a very advanced stage of disease. The other organs only showed signs of age, most marked in the kidneys which were tougb, pliant, and had confused cortices. The brain was soft and œdematous but no gross lesion was present.

Remarks by Dr. MoRRIs, - The above case appears to be of sufficient interest to warrant recording. It is much to be regretted that fuller notes of the condition ante mortem cannot be given. The patient had apparently died from a failure of the right heart, due, it may be, to degenerative muscle changes taking place about the site of the bullet. No microscopic sections were made as the specimen was desired undisturbed.

My thanks are due to those members of the honorary medical staff, under whose care the patient was, for permission to publish these notes.

\section{ittledical Sortetties.}

\section{EDINBURGH MEDICO-CHIRURGICAL SOCIETY.}

Ruptured Gastrio Ulcer in a Boy.-O Operation for Perforating

Gastric and Duodenal Ulcer.-Exhrbition of Epeoimens.

A MEETING of this society was held on July 4th, Dr. J. O. AFFLECK, the President, being in the chair.

Dr. G. KEPPIE PATERSON read notes on a case of Ruptured Gastric Ulcer in a boy, aged 12 years. The patient had suffered from pain after eating, indefinite as to position and time after food; sometimes there was no pain after a meal. There was no vomiting or flatulence and the tongue was very slightly furred. The pain continued for 12 days, being only partly relieved by treatment, when after a light dinner in the evening he suddenly felt very severe pain in the abdomen. He was seen an hour afterwards when he was collapsed, with slow pulse, rigid abdomen, normal temperature, and complaining of pain in the abdomen and also in the left shoulder, especially about the left clavicle. After the application of $a$ fomentation and gentle friction all signs of shock disappeared in half an hour ; there was no loss of liver dulness. On the next morning he had signs of peritcnitis with loss of liver dulness in front. He was operated on by Dr. F. M. Caird 18 hours after the rupture. A ruptured ulcer of the size of a small split pea was found on the anterior wall about two inches 